\title{
A rare cause of dysphagia: compression of esopha- gus by a giant thoracic spine osteophyte
}

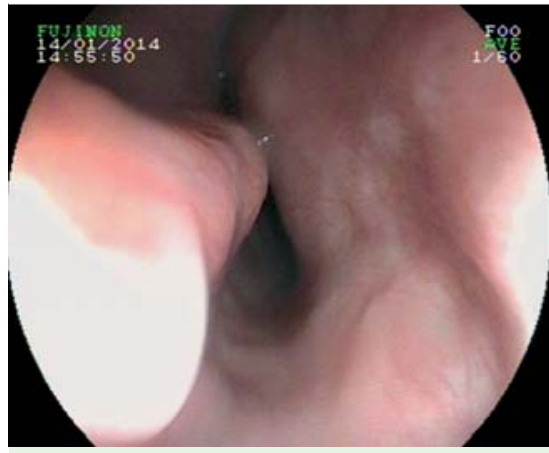

Fig. 1 Endoscopy showing a smooth, extrinsic indentation on the left posterior wall of the mid-esophagus.

A 76-year-old man presented to our department complaining of dysphagia which had started 6 months earlier as mild and had gradually progressed for the last month. He indicated that it was mainly limited to solids and was relieved by fluids. He had no pain while swallowing. The patient was a nonsmoker and his medical history included hypertension and osteoarthritis. An upper gastrointestinal endoscopy was performed and revealed a smooth, extrinsic indentation on the left posterior wall of the mid-esopha- gus ( $\bullet$ Fig. 1). The esophagus appeared otherwise normal without any evidence of the formation of any intrinsic structure. Cervical-thoracic computed tomography (CT) was performed for differential diagnosis. This revealed fusion between the T2-T5 corpora and diffuse idiopathic skeletal hyperostosis (DISH), with prominent osteophyte formation projecting anteriorly on the left at the T2-T3 level. This formation pressed on the esophagus, as shown in the CT image ( $\bullet$ Fig. 2 ). Severe dysphagia related to thoracic osteophytes was diagnosed. A surgical consultation was arranged and an operation for osteophyte excision was proposed. However, the patient refused surgical intervention, so diet modification and antireflux and swallowing therapy were prescribed and explained to him.

Dysphagia is a common problem in older patients and is becoming a larger health care problem. Dysphagia can occasionally be caused by giant vertebral osteophytes or exuberant bone formation associated with DISH. Almost all reported cases have resulted from large anterior osteophytes in the cervical spine, which commonly involve the hypopharynx or the cervical

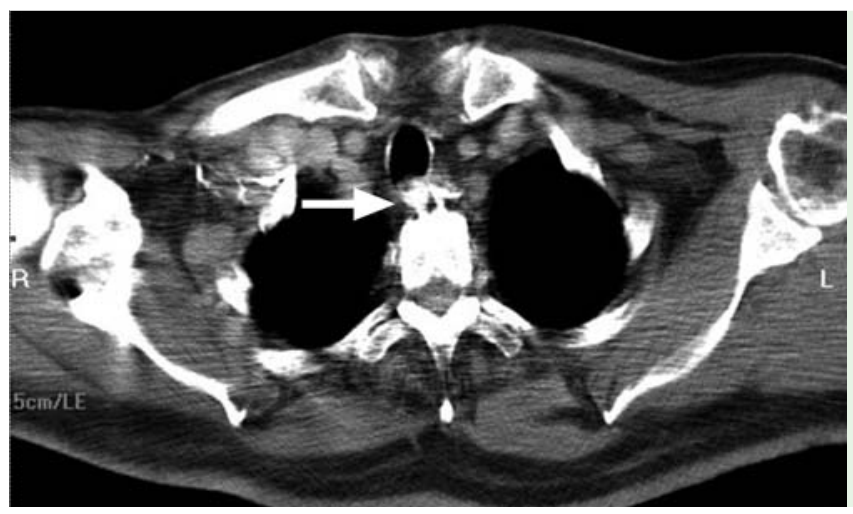

Fig. 2 Computed tomography showing a giant thoracic osteophyte formation (white arrow) extending anteriorly $2 \mathrm{~cm}$ from the intervertebral junction at the level of the second thoracic vertebra on the left, compressing the esophagus. esophagus. It has been suggested that osteophytes are more likely to cause narrowing of the cervical esophagus, because in the cervical spine the cricoid cartilage fixes the esophagus, whereas the thoracic esophagus is a relatively mobile structure that can be displaced anteriorly or laterally without being compressed [1], and for this reason dysphagia related to thoracic esophagus involvement is very rare [2].

Endoscopy_UCTN_Code_CCL_1AB_2AC_3AD

Competing interests: None

\section{Serta Kilincalp ${ }^{1}$, Hakan Akıncı ${ }^{1}$, Özlem Aygin İsak ${ }^{1}$, Şahin Çoban ${ }^{1}$, ilhami Yüksel ${ }^{1,2}$}

${ }^{1}$ Dışkapı Yıldırım Beyazıt Education and Research Hospital, Department of Gastroenterology, Ankara, Turkey

2 Yılırım Beyazıt University School of Medicine, Department of Gastroenterology, Ankara, Turkey

\section{References}

1 Rana SS, Bhasin DK, Rao C et al. Thoracic spine osteophyte causing dysphagia. Endoscopy 2012; 44: E19-20, doi: 10.1055/s0031-1291501

2 Underberg-Davis S, Levine MS. Giant thoracic osteophyte causing esophageal foodimpaction. AJR Am J Roentgenol 1991; 157: 319 320

\section{Bibliography}

DOI http://dx.doi.org/

10.1055/s-0034-1365795

Endoscopy 2015; 47: E1

(c) Georg Thieme Verlag KG

Stuttgart · New York

ISSN 0013-726X

Corresponding author

Serta Kilincalp, MD

Ankara İrfan Baştuğ Caddesi Dışkapı

06610 Ankara

Turkey

Fax: +90-312-3186690

serta80@gmail.com 